\title{
Correction to: Investigation of deformations with the GNSS and PSInSAR methods
}

\author{
Osman Oktar ${ }^{1} \cdot$ Hediye Erdoğan ${ }^{1} \cdot$ Fatih Poyraz ${ }^{2} \cdot$ İbrahim Tiryakioğlu ${ }^{3}$
}

Published online: 20 December 2021

(c) Saudi Society for Geosciences 2021

\section{Correction to: Arabian Journal of Geosciences (2021) 14:2586} https://doi.org/10.1007/s12517-021-08765-x

In this article, Figs. 9 and 10 are duplicate. Given here are the correct figures.

The original article has been corrected.

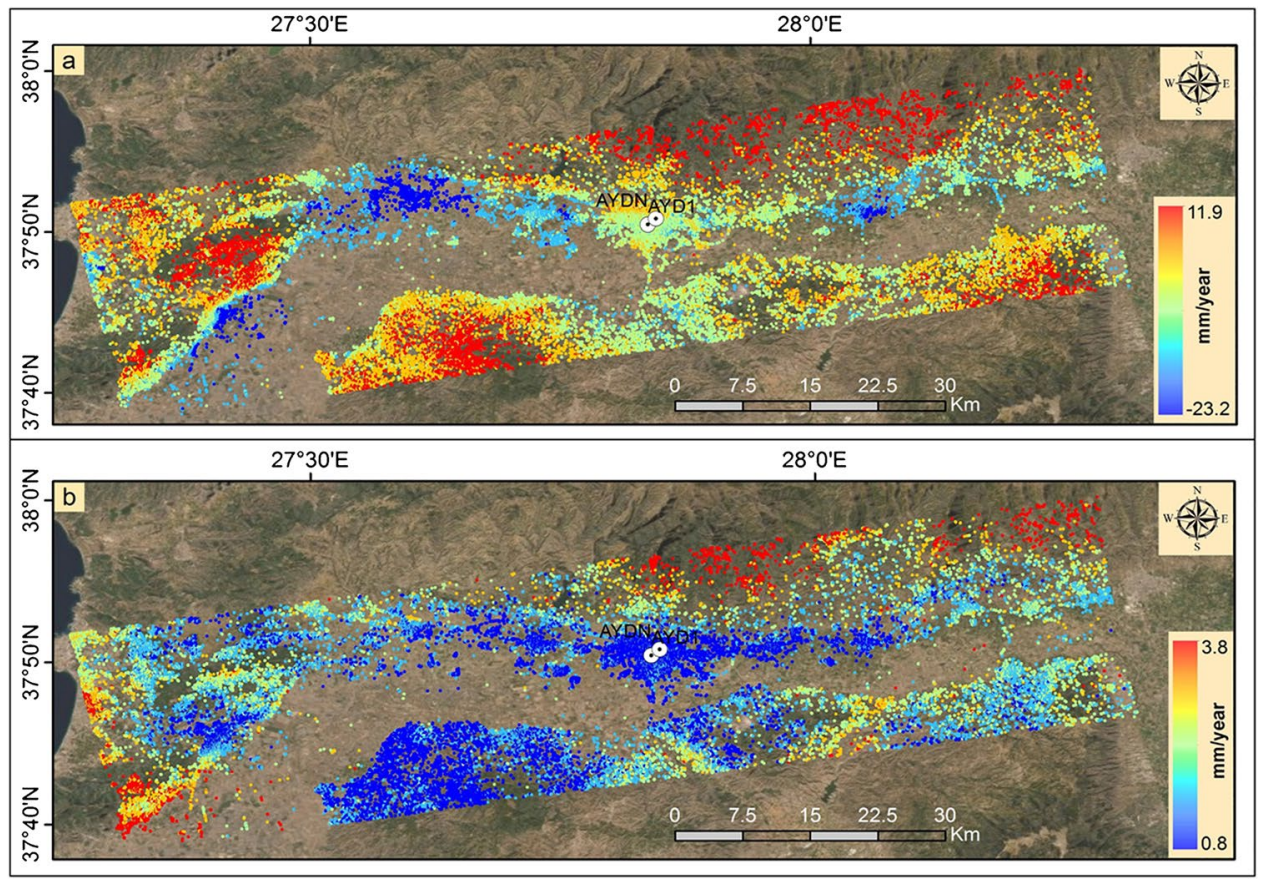

The original article can be found online at https://doi.org/10.1007/ s12517-021-08765-x.

\section{Osman Oktar}

osman.oktar38@gmail.com

1 Department of Geomatics Engineering, Engineering Faculty, Aksaray University, Aksaray, Turkey
2 Department of Geomatics Engineering, Engineering Faculty, Sivas Cumhuriyet University, Sivas, Turkey

3 Department of Geomatics Engineering, Engineering Faculty, Afyon Kocatepe University, Afyonkarahisar, Turkey 


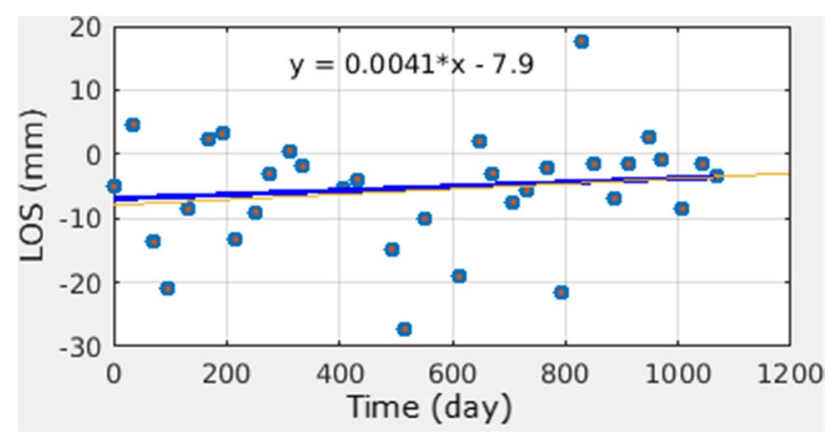

